\title{
Interactive comment on "Solar tracker with optical feedback and continuous rotation" by John Robinson et al.
}

\section{John Robinson et al.}

john.robinson@niwa.co.nz

Received and published: 3 September 2020

The comment was uploaded in the form of a supplement:

https://amt.copernicus.org/preprints/amt-2020-223/amt-2020-223-AC2-

supplement.pdf

Interactive comment on Atmos. Meas. Tech. Discuss., doi:10.5194/amt-2020-223, 2020. 